\title{
Reflexões sobre Água, Sabão e Conhecimento: Aprendizagem Organizacional na Prática das Serventes de Limpeza de uma Instituição de Ensino Federal
}

\author{
Viviani Teodoro Santos \\ Universidade Tecnológica Federal do Paraná e Universidade Estadual de Maringá - Brasil \\ vivi_adm3@hotmail.com \\ Marcio Pascoal Cassandre \\ Universidade Estadual de Maringá - Brasil \\ mcassandre@hotmail.com \\ http://orcid.org/oooo-ooo1-9415-4315
}

\section{Resumo}

Em razão da multiplicidade de abordagens e da complexidade do tema, a Aprendizagem Organizacional dificilmente poderia ser entendida por meio de conceitos únicos ou estanques. Um mundo de desafios e possibilidades se abre no estudo dessa temática, e refletir sobre os diversos caminhos faz parte do processo de aproximação do tema. Sendo assim, o presente artigo tem como objetivo conhecer o processo de aprendizagem das serventes de limpeza terceirizadas de uma instituição pública de Ensino Superior, e para alcançá-lo buscam-se respostas para quatro questões específicas: 1.Como as serventes aprenderam sua profissão? 2. Quais os impactos na aprendizagem, de um serviço terceirizado por parte das pesquisadas? 3. Qual a capacidade de interferência da gestão da instituição no processo de aprendizagem? 4. Como conduzir o processo de aprendizagem para solucionar a problemática? Mediante pesquisa qualitativa, composta por entrevistas individuais, grupos focais, bem como a utilização da autoconfrontação simples, observou-se que a aprendizagem do grupo provém de uma prática cotidiana fortemente vinculada às suas histórias de vida. Uma aprendizagem construída no coletivo, por meio das interações sociais, mediada por artefatos físicos e simbólicos e influenciada por uma dupla cultura organizacional, por um juízo estético, por um pensar vinculado ao fazer e por uma capacidade transformadora da própria atividade por parte das sujeitas. Nesse sentido, 
entende-se que uma alternativa apropriada para um futuro trabalho seria a opção por metodologias intervencionistas em razão de serem capazes de proporcionar um espaço de reflexão e participação, em que as contradições possam ser trabalhadas de forma cíclica, transformando os envolvidos em sujeitos ativos e autores da própria trajetória de mudanças, tanto no âmbito profissional quanto pessoal.

Palavras-Chave: aprendizagem organizacional, serventes de limpeza, prática, terceirizados. 


\title{
Reflections on Water, Soap and Knowledge: Organizational Learning in the Practice of Cleaning Servants of a Federal Education Institution
}

\author{
Viviani Teodoro Santos \\ Universidade Tecnológica Federal do Paraná e Universidade Estadual de Maringá - Brasil \\ vivi_adm3@hotmail.com \\ Marcio Pascoal Cassandre \\ Universidade Estadual de Maringá - Brasil \\ mcassandre@hotmail.com \\ http://orcid.org/oooo-ooo1-9415-4315
}

\begin{abstract}
Because of the multiplicity of approaches and the complexity of the theme, Organizational Learning could hardly be understood through single or closed concepts. A world of challenges and possibilities opens up in the study of the thematic and, to reflect on the different paths, is part of the very process of approaching the theme. Thus, the present article aims to know the learning process of outsourced cleaning servants of a public institution of higher education, and in order to reach it will seek answers to four specific questions: 1. How the servants learned their profession? 2. What are the impacts in the learning, of an outsourced service, by the surveyed? 3. What is the interference capacity of the institution's management in the learning process? 4. How to conduct the learning process to solve the problem? Through a qualitative research, made up of individual interviews, focus groups, and the use of simple self-confrontation, it was realized that the group learning comes from a strongly bound everyday practice to their life stories. A learning built collectively, through social interactions mediated by physical and symbolic artifacts and influenced by a dual organizational culture, an aesthetic judgment, by a thinking bound to do and a manufacturing capacity of their own activity by the subject. In this sense, it is understood that an appropriate alternative for a future work would be the option for interventionist methodologies, because they are capable of providing a space for
\end{abstract}


reflection and participation, in which contradictions can be worked in a cyclical way, transforming those involved in active subjects and authors of their own history of changes, both in the professional and personal.

Keywords: organizational learning, cleaners, practice, outsourced. 


\section{Introdução}

Em busca de ferramentas que lhes proporcionem melhorias, seja em suas instalações físicas, estratégias comerciais, financeiras ou em seus recursos humanos, as organizações estão cada vez mais interessadas tanto em novas tecnologias quanto em novas formas de gerir as pessoas. Nesse sentido, a temática da Aprendizagem Organizacional tem despontado nos estudos organizacionais como meio compreender, mensurar e estimular a aprendizagem do sujeito, e porque não, da organização, com vistas à mudança organizacional.

Na busca por respostas para a pergunta: “O que é Aprendizagem Organizacional?", porém encontra-se um difícil desafio, pois esse movimento leva a múltiplas reflexões. Em um primeiro momento esse processo se mostra confuso, antagônico, conflituoso, mas nessa jornada há uma opção de, ao invés de tentar encontrar uma resposta única, começar a enxergar essa complexidade com uma riqueza de elementos capaz de provocar um dinâmico processo de reflexão que, por fim, esteja mais próximo a uma relação de complementaridade do que de dicotomia.

Ao considerar que a trajetória de desenvolvimento dessa temática, tem recebido contribuições de diferentes perspectivas, provenientes de distintas áreas da ciência, é preciso esclarecer que, a aprendizagem neste estudo, é entendida mais como processo do que como resultado; mais como inerente ao sujeito vinculado à organização do que à própria organização como ente reificado; mais como processo coletivo do que individual, e uma compreensão de aprendizagem não vinculada apenas a uma capacidade cognitiva, mas também social.

Portanto, pode-se afirmar que a Aprendizagem Organizacional vai além de mensuração e solução de problemas, uma vez que apresenta múltiplos elementos subjetivos que não são facilmente controlados por pesquisadores ou organizações. Nesse âmbito, a problemática deste estudo pode ser retratada mediante da seguinte pergunta: Como se dá o processo de aprendizagem das serventes de limpeza terceirizadas de uma instituição pública de Ensino Superior?

Com a finalidade de alcançar o objetivo geral de conhecer o processo de aprendizagem das serventes de limpeza, a aproximação empírica busca respostas para quatro questões 
específicas: 1. Como as serventes aprenderam sua profissão? 2. Quais os impactos, na aprendizagem, de um serviço terceirizado por parte das pesquisadas? 3. Qual a capacidade de interferência da gestão da instituição no processo de aprendizagem? 4. Como conduzir o processo de aprendizagem para solucionar a problemática?

Ao levar em conta o caráter multiparadigmático da temática e a ausência de teorias da aprendizagem organizacional abrangentes que abarquem o fenômeno por completo, este estudo não é guiado por uma abordagem específica, para que se evitem limitações no sentido de se tentar encaixar o fenômeno apreendido em uma abordagem específica. Desse modo, opta-se por um conjunto de abordagens - Aprendizagem pela prática, Abordagem Cultural, Abordagem Social e Teoria da Atividade Histórico-Cultural - que partem de um conceito de aprendizagem relacional, uma aprendizagem nascente das interações humanas mediadas. Sendo assim, tanto as ferramentas metodológicas como a análise dos resultados são pautadas nesse conjunto de abordagens.

Dada as diferentes abordagens na Aprendizagem Organizacional, as múltiplas formas de visão de mundo e compreensão dos temas em estudos organizacionais, faz-se necessário esclarecer que as perspectivas escolhidas para compor este artigo integram uma compreensão ontológica que considera o homem não como um indivíduo determinado pela natureza, mas como sujeito com capacidade de transformar sua própria realidade e a do mundo no qual está inserido.

Como pressupostos epistemológicos, servem de base para o propósito deste artigo o interpretativismo enquanto intenção de compreender a realidade a partir das múltiplas perspectivas. No interpretativismo, “a intenção do pesquisador, então, é compreender (ou interpretar) os significados que os outros tem sobre o mundo" (Creswell, 2014, p. 36).

Como conceitos essenciais metodológicos, acredita-se na necessidade de compreender o papel do pesquisador como agente de mudança e não apenas observador passivo da situação analisada, e entender a investigação como um processo construtivo-interpretativo e histórico em constante mudança, valorizando não só as práticas discursivas que se revelam nas análises dos materiais, mas, também, a legitimidade das ideias do pesquisador (Cassandre \& Godoi; 2014).

Em relação ao nível de análise deste estudo, convém esclarecer que a proposta aqui contida diz respeito a uma aproximação para conhecer as práticas de trabalho de um grupo 
pequeno e específico de trabalhadoras terceirizadas inseridas em uma instituição com mais de 150 servidores, portanto não se pretende com isso fazer inferências sobre a aprendizagem da organização, sua capacidade de retenção ou estímulo à aprendizagem, mas pensar na aprendizagem do sujeito, sobretudo do sujeito inserido em uma coletividade.

No que se refere à importância do estudo como contribuição teórica para o tema da Aprendizagem Organizacional, acredita-se que a pesquisa possa ser o primeiro passo na direção daquilo que Nogueira e Odelius (2015) apontam como desafio metodológico. Apesar de, nesse momento, o foco não ser o desenvolvimento ou implementação de um modelo da aprendizagem, representa uma primeira aproximação do campo no intuito de compreender a aprendizagem para na sequência, pensar novas formas de modelos de investigação e ação, contribuindo tanto teórica quanto metodologicamente com a temática.

Além disso, para os estudos organizacionais, investigar um grupo de trabalhadoras de limpeza, que executam um trabalho classificado como de baixa complexidade, representa um olhar diferente da forma dominante de pesquisa que geralmente se interessa pelos altos cargos de modo a munir gestores de estratégias capazes de otimizar a gestão empresarial. A presente experiência é uma maneira de acolher o outro, de reconhecer que o trabalhador simples, operário, por meio de seu conhecimento popular, geralmente não reconhecido como científico, também pode possibilitar ganhos teóricos válidos para os estudos organizacionais.

O interesse desta pesquisa surgiu da relação de um dos pesquisadores com os sujeitos investigados, uma vez que faz parte do quadro de servidores da instituição de ensino e desempenha a função de fiscal do contrato firmado com a empresa prestadora do serviço de limpeza. Dentre as justificativas práticas que despertaram o interesse de pesquisa estão: a) a necessidade de aproximação da prática do serviço de limpeza, uma vez que na função de fiscal, o excesso de exigências legais o leva a empregar maior esforço no aspecto documental do contrato, distanciando-se do acompanhamento dos serviços prestados, mantendo o foco apenas no resultado final e não nas nuances do processo; b) maior cobrança, por parte da gestão da instituição, pela redução do consumo de energia elétrica, água e materiais de limpeza, visando à economia de recursos; c) necessidade de implantação de práticas sustentáveis; d) os escassos resultados obtidos nas tentativas de padronização visando ao racionamento de materiais. 
Quanto aos procedimentos metodológicos, pensando em uma maneira de investigação capaz de apreender mais do que modos e formas, capturando sutilezas desta prática cotidiana, a opção foi pela pesquisa qualitativa, composta por entrevistas individuais, grupos focais, bem como a utilização da autoconfrontação simples, que proporciona ao sujeito de pesquisa uma reflexão sobre sua própria prática de trabalho por meio das diversas oportunidades de relatar, repensar e reformular sua percepção.

$\mathrm{Na}$ primeira parte do artigo apresentam-se quatro abordagens da Aprendizagem Organizacional e após a descrição metodológica, inicia-se a reflexão acerca das quatro perguntas centrais do estudo, intercalando desenvolvimento teórico e apresentação dos dados coletados, encerrando-se com as considerações finais.

\section{Aprendizagem Organizacional: as várias compreensões}

Ao abordar a Aprendizagem Organizacional (AO), o primeiro passo seria entendê-la como uma temática amplamente estudada e discutida por diversas áreas do conhecimento, o que leva a uma multiplicidade de enfoques. Por se tratar de um tema difundido e analisado por diversas lentes, e muitas vezes de modo inconsistente, a Aprendizagem Organizacional, por vezes, acaba sendo interpretada como uma temática complexa e confusa.

Apesar da fragilidade do tema, é preciso tratar a temática como um mundo de possibilidades, em que uma hipótese não necessariamente exclua a outra, em que o "certo" e o "errado" são divididos por uma linha fina, e isso pode levar a uma perspectiva otimista em relação ao futuro dos estudos em Aprendizagem, em que essa diversidade de questões a serem refletidas, traga novas perspectivas e avanços para o tema (Bitencourt \& Azevedo, 2006).

Para Antonello e Godoy (2010), é possível que a sua popularidade possa ter trazido a perda da especificidade de seu próprio conceito, muitas vezes entendido como conceito guarda-chuva, e que o risco em abraçar essa diversidade seria a perda de sua identidade própria.

A partir dos anos 50 e 60 do século $\mathrm{XX}$ a pesquisa em $\mathrm{AO}$ passa a incluir insights da Psicologia, Sociologia, Ciência da Computação e Economia. Em razão da pluralidade da 
produção em AO, surgiu uma classificação da literatura em diferentes disciplinas, escolas de pensamento ou perspectivas, e até mesmo dentro da mesma área existam diferentes perspectivas. (Antonello \& Godoy, 2011)

Diante disso, talvez o caminho seja compreender AO por meio de uma visão multiparadigmática, considerando as diversas perspectivas que já contribuíram e têm contribuído com a temática ao longo do tempo (Antonello \& Godoy, 2010). Weick e Wesley (2004) assinalam ser possível que a dificuldade de se conceituar AO primeiramente esteja atrelada à dificuldade de se conceituar "organizações" e "aprendizagem": "Organizar e aprender são essencialmente processos antagônicos, o que significa que a expressão aprendizagem organizacional é um oximoro. Aprender é desorganizar e aumentar a variedade. Organizar é esquecer e reduzir a variedade. Os teóricos organizacionais negligenciam esta tensão" (Weick \& Wesley, 2004, p. 361).

Ao discutir os desafios da pesquisa em AO, Nogueira e Odelius (2015), após revisão de literatura, apresentam as quatro fontes mais citadas e mais influentes do campo: Argyris e Schön $(1978 ; 1996)$, que consideram a aprendizagem como processo de detecção e correção de falhas; Daft e Weick (1984), para os quais a interpretação organizacional de traduzir eventos e desenvolver conhecimentos precede a aprendizagem, e faz com que as organizações preservem conhecimentos e valores; Levitt e March (1988), que também concordam com o fato de que as organizações são capazes de codificar e armazenar conhecimento independente da rotatividade de pessoa e Fiol e Lyles (1985) que compreendem que aprendizagem organizacional ocorre por meio das histórias transferidas ao longo do tempo e que essa aprendizagem é capaz de mudança comportamental e cognitiva.

Nesse processo, percebe-se uma acentuada preocupação em definir limites, encontrar respostas únicas e chegar, enfim, a uma aplicabilidade da Aprendizagem. Mas nessa busca por novas soluções práticas, há de se passar por inúmeras reflexões e redefinições, não só em razão das inúmeras abordagens existentes, mas também pelo caráter transitório das próprias organizações.

Diante dessa multiplicidade de enfoques, e considerando os pressupostos ontológicos e epistemológicos deste estudo, quatro abordagens são trabalhadas: a) Aprendizagem pela 
prática; b) Abordagem Cultural da Aprendizagem; c) Abordagem Social da Aprendizagem;

d) Teoria da Atividade Histórico-Cultural.

\section{Aprendizagem pela Prática}

Para as abordagens baseadas na prática (Geiger, 2009; Whittington, 2006; Jarzabkowski, 2005; Reckwitz, 2002), a aprendizagem não deve mais ser entendida apenas como um processo mental individual ou o conhecimento, entendido como uma mercadoria, pois isso seria entendê-la como objeto e não como um processo. É preciso entender o conhecimento no contexto do acontecimento, criação ou transferência. Nesse contexto, as teorias com base na prática sustentam que o pensar e o fazer estão intimamente ligados e que o ser que aprende não pode ser desconectado do seu mundo no momento em que se estuda o seu processo mental, uma vez que o pensamento e o mundo estão sempre ligados por meio da atividade humana, pois são inseparáveis.

Como características em comum das abordagens baseadas na prática destacam-se: a evocação de um mundo que está sempre em construção, em que o "fazer", mais do que "ser" está no centro das atenções; o fato da localização do conhecimento não estar na mente do indivíduo, mas no sujeito social, um sujeito que pensa ao mesmo tempo que aprende e trabalha; a socialização do sujeito com artefatos e material simbólico não serem vistos apenas como pano de fundo, mas participantes ativos no processo, e por fim, a preocupação com o espaço temporal da aprendizagem.

O local em que se deve, portanto, buscar respostas para as diversas questões que permeiam os conceitos e abordagens de $\mathrm{AO}$ é no ambiente de ação desse indivíduo que aprende. Esse ambiente não é algo previsível e muito menos facilmente controlável como a visão funcionalista descreve:

No mundo descrito por termos com base na prática, as pessoas agem e interagem, mas elas também olham, ouvem, e ignoram o outro. Eles têm corpos; eles tocam, cheiram, saboreiam; eles têm sentimentos e sentidos; eles argumentam, gritam, têm medo, ficam nervosos, e até 
mesmo morrem. Eles não são apenas entidades sociais efêmeras (agentes); eles são seres que habitam um mundo da vida que, longe de constituir um "problema", são o próprio objeto de estudo e representação desta abordagem. (Nicolini et al., 2003, p.22)

Esse espaço de aprendizagem deve ser visto como um espaço de interação entre pessoas e artefatos, que utilizando-se da linguagem e de outros sinais e expressões únicas, imprimem nesse processo um nível ainda maior de complexidade, pois não faz mais sentido separar sujeito, objeto, pensamento ou contexto, pois todos são parte de uma situação existente em um ambiente social e histórico e, assim, a prática passa a ser vista tanto como produção do conhecimento como seu resultado.

\section{Abordagem Cultural da Aprendizagem}

A abordagem cultural da aprendizagem (Yanow, 2000; Weisinger \& Salipante, 2000; Cook \& Yanow, 1993) permite olhar determinadas sutilezas no ambiente em que ocorre a aprendizagem, que talvez não sejam consideradas em outras abordagens. Ela aparece como alternativa às abordagens cognitivas que conferem às organizações a mesma capacidade e formato de aprendizagem do indivíduo.

O fato de as abordagens cognitivas tratarem o processo de aprendizagem de forma padronizada, como se indivíduos e organizações aprendessem da mesma forma, é rechaçada aqui, principalmente pelo motivo das organizações não possuírem corpos ou cérebros. Não que isso defina que as organizações sejam incapazes de aprender, mas essa explicação deve respeitar alguns limites, inclusive ao declarar a $\mathrm{AO}$ como a soma das aprendizagens individuais.

Em particular, nós argumentamos que o que as organizações fazem quando aprendem é necessariamente diferente do que as pessoas fazem quando elas aprendem. Especificamente, acreditamos que a 
aprendizagem organizacional não é essencialmente uma atividade cognitiva, porque, no mínimo, falta às organizações a possibilidade peculiar para empreender cognição: Elas não possuem o que as pessoas possuem e usam em conhecimento e aprendizagem, isto é, corpos reais, órgãos perceptivos, cérebros, e assim por diante (Cook \& Yanow, 1993, p. 378).

O foco da perspectiva cultural também está na aprendizagem coletiva, e nesse momento a pergunta passa de “Quem aprende?” para “Como aprende?”. A Aprendizagem, portanto, não está necessariamente vinculada à mudança, pois nem sempre se obtêm resultados, ou ainda os resultados esperados, pois esse processo se dá na interação, na troca, num compartilhamento permeado por uma cultura, e isso o torna imprevisível.

Esta cultura, retrata um conjunto de valores, crenças, sentimentos, artefatos, mitos, símbolos, rituais, que são criados, herdados e transmitidos por pessoas e grupos de pessoas que, de certa maneira, também distinguem esses grupos. Sendo assim, não se considera a existência de apenas uma cultura, mas "culturas”, que nesta dinâmica podem ser mantidas ou modificadas ao longo do tempo (Cook \& Yanow, 1993).

\section{Abordagem Social da Aprendizagem}

Com intuito de buscar uma re-conceituação de AO, a Abordagem Social da Aprendizagem (Freitas \& Godoi, 2008; Antonacopoulou \& Chiva, 2007; Elkjaer, 2005) lança mão de elementos como a incerteza e criatividade, e mostra que $\mathrm{AO}$ precisa mais que um foco na aprendizagem individual, cognitiva ou coletiva, uma vez que essa discussão pode levar a um reducionismo lógico que empobreceria a temática.

Antonacopoulou e Chiva (2007), trabalhando a perspectiva da complexidade social elencam três dimensões que servem de base para capturar a dinâmica da aprendizagem nas organizações: o envolvimento do poder e da política, a multiplicidade dos níveis de aprendizagem e a inter-conectividade entre as forças internas e externas. 
Ainda nessa linha, Elkjaer (2005) propõe uma terceira via de AO que poderia ser definida como o desenvolvimento de experiências e conhecimentos por meio de inquérito ou pensamento reflexivo em mundos sociais, com implicações práticas de trazer à tona intuição e emoção.

Por meio da análise minuciosa de pormenores, cria-se uma visão mais integradora, combinando os níveis de aprendizagem: indivíduo, grupo, organização e ambiente, adotando uma nova unidade de análise voltada para os eventos e situações. Aqui, o contexto e a situação vivenciada tornam-se determinantes na interpretação do estímulo e na escolha da ação, não mais separando corpo e mente, mas considerando o corpo, as emoções e a intuição como partes cruciais do processo de aprendizagem.

Quanto mais avançam as reflexões, mais o ambiente organizacional e os sujeitos da aprendizagem vão perdendo a característica de passividade e determinismo, colocando em dúvida a tradicional ideia da facilidade de controle dos indivíduos e contextos por parte da organização. Não que métodos prescritivos não sejam úteis ou importantes no contexto organizacional, mas nem sempre seu processo de aplicação e replicação se dará assim de modo tão simples e lógico, porque trata-se de um ambiente vivo, dinâmico, cercado de pessoas, que à medida que estão implicadas, entregues a esse processo, precisam ser entendidas e acolhidas na sua integralidade, pois estão impregnadas por uma história de vida e situadas em um contexto geográfico, cultural, histórico e social específicos que, independente da força empregada na busca por resultados, em algum momento esses elementos virão à tona, imprimindo sua marca no processo.

\section{Teoria da Atividade Histórico-Cultural}

Como mencionado, muitas são as contribuições de outras áreas da ciência à Aprendizagem Organizacional, por conseguinte a Teoria da Atividade Histórico-Cultural (TAHC) representa a contribuição da área da educação à temática. Paes de Paula e Palassi (2007) esclarece que as ideias de Vygotsky já têm sido trabalhadas nas áreas da Educação e da Psicologia desde 196o e agora têm sido trabalhadas nos estudos organizacionais.

Entretanto, no que tange a Aprendizagem Organizacional brasileira, este aporte teve seu início em 2011, com os trabalhos de Pereira-Querol, Jackson-Filho e Cassandre (2011) e 
Cassandre, Pereira-Querol e Bulgacov (2012). Abre-se, desse modo, o caminho para a Teoria da Atividade Histórico-Cultural, que passa acreditar em uma aprendizagem organizacional que considera o sujeito com uma potencialidade de vir a ser, em que essa capacidade de agência pode e será aproveitada de modo contínuo em busca de transformações.

A Teoria da Atividade Histórico-Cultural, iniciada por Lev Vygotsky na década de 1920, trabalha o conceito de atividade mediada entre indivíduo e artefato em seguida, na segunda geração essa relação de mediação é expandida do individual para o coletivo e na terceira geração, passam também a ser consideradas as redes de interação entre os vários sistemas de atividade.

A inserção de artefatos culturais nas ações humanas foi revolucionário quando a unidade básica de análise superou a cisão entre indivíduo cartesiano da estrutura social intocável. O indivíduo já não podia ser compreendido sem os seus meios culturais e a sociedade já não podia ser entendida sem a agência de indivíduos que utilizam e produzem artefatos. (Engeström, 1996, p. 132)

Ao pensarmos principais conceitos da Teoria da Atividade Histórico-Cultural transpostos para $\mathrm{AO}$, destaca-se a noção de que o ambiente social não é apenas um fator a ser considerado no processo de desenvolvimento, mas uma fonte de desenvolvimento. Para Veresov (2010, p. 84), “o desenvolvimento da mente humana não é biológico, mas sim um processo social-cultural".

Nesse seguimento, a aprendizagem não pode ser vista como um resultado, adquirido por exemplo, por meio de um processo de imitação ou repetição de uma prática. A aprendizagem antecede o desenvolvimento, trata-se de um processo de contato, mediação e assimilação com possibilidade de despertar um possível resultado:

Desse ponto de vista, aprendizado não é desenvolvimento; entretanto, o aprendizado adequadamente organizado resulta em 
desenvolvimento mental e põe em movimento vários processos de desenvolvimento que, de outra forma, seriam impossíveis de acontecer. Assim, o aprendizado é um aspecto necessário e universal do processo de desenvolvimento das funções psicológicas culturalmente organizadas e especificamente humanas. (Vygotsky, 1978, p.35)

Após três gerações e diversas fases de expansão, a Teoria da Atividade atualmente, segundo Engeström (2001), poderia ser resumida em cinco princípios. O primeiro é que um sistema de atividade é sempre coletivo, mediado por artefatos, orientado para um objeto e mesmo sendo a principal unidade de análise, deve ser visto sempre em relação a uma rede de outros sistemas de atividade. O princípio da historicidade refere-se ao fato de que esses sistemas estão sempre se transformando durante longos períodos de tempo e essa história deve ser estudada para que haja compreensão dos problemas atuais e das potencialidades.

Outro princípio importante trata do papel central das contradições como "fontes de mudança e de desenvolvimento". Diferente de conflitos ou problemas, as contradições são “tensões estruturais historicamente acumuladas dentro e entre os sistemas de atividade". Por conseguinte, o princípio da possibilidade de transformações expansivas nos sistemas de atividade refere-se à movimentação e transformação desses sistemas, em razão do agravamento das contradições; nesse caso, surge a necessidade de transformação expansiva que ocorre quando o objeto e o motivo da atividade são reconceituados, ampliando o horizonte da atividade (Engeström, 2001, p. 137).

Deixado por último propositalmente, para destacá-lo, apresenta-se o princípio da multivocalidade do sistema de atividade. Segundo Engeström (2001, p.136), esse princípio assume que o sistema de atividade é "sempre uma comunidade com múltiplos pontos de vista, tradições e interesses", em que os participantes envolvidos possuem posições diferentes e por isso suas próprias histórias. Além disso, os próprios artefatos, regras e convenções têm histórias gravadas em si. Essa multivocalidade, além de representar uma fonte de problemas é também “fonte de inovação, exigindo ações de tradução e negociação”. 
É importante salientar que nesse processo de aprendizagem travado no social, nas interações, é bastante sensível por parte da teoria da atividade considerar essa multivocalidade própria do coletivo. Um coletivo repleto de variadas histórias e dilemas que diferem em seus detalhes, mas que talvez num olhar mais amplo podem estar vinculados a uma contradição em comum. Essa multivocalidade não precisa ser abafada em nome de uma urgente necessidade de consenso, uma vez que, na Teoria da Atividade, ela passa a ser matéria-prima para a investigação da contradição e para a prática da negociação entre os pares em prol de uma reconceituação da própria atividade.

Quanto aos princípios epistemológicos da Teoria da Atividade, salienta-se igualmente, a estimulação dupla, na qual o indivíduo, a partir do primeiro estímulo, que geralmente é o problema em si, se apropria de artefatos externos, dando a eles novos significados, utilizando-os como segundo estímulo e apoio na resolução da contradição, construindo uma nova compreensão e encontrando um significado até então inexistente. De acordo com Sannino (2011), a estimulação dupla é apresentada como um fator-chave para a capacidade humana de transformar ao mesmo tempo o mundo e a si mesmo.

Nesse sentido, a história filogenética do intelecto prático do homem está intimamente ligada, não só para dominar a natureza, mas também para dominar a si mesmo. A história de trabalho e de expressão que dificilmente pode ser compreendida sem o outro. O homem não só inventou ferramentas, por meio das quais ele conquistou a natureza, mas ele também inventou estímulos que tem motivado e regulamentado seu próprio comportamento e por meio dos quais ele tem subjugado suas próprias forças à sua vontade. (Vygotsky \& Luria, 1994, p. 164, apud Sanino, 2011, p. 15)

Nesse aspecto, a Teoria da Atividade, considerada como intervencionista, (Cassandre \& Godoi, 2014; Pereira-Querol et al., 2014; Sannino, 2011; Engeström, 2001) apresenta 
capacidades metodológicas capazes de promover um espaço no qual o sujeito tem a possibilidade de tomar as rédeas, sair da condição de indivíduo determinado e transformarse, ao mesmo tempo que transforma a natureza com a qual se relaciona.

Diante das quatro abordagens apresentadas, é preciso esclarecer que cada uma delas contribui com a análise dos achados de pesquisa, uma vez que todas estão voltadas a uma aprendizagem que vai além do aparato cognitivo individual, pois acontece por meio de trocas e interações em uma coletividade, por meio de uma conexão íntima entre o pensar e o fazer, influenciada por elementos culturais, sociais e mediadas por artefatos concretos ou simbólicos.

\section{Procedimentos Metodológicos}

Ao analisar o processo de aprendizagem entre as serventes de limpeza, foi utilizada uma abordagem qualitativa, que tem seu interesse voltado a examinar quais os significados são atribuídos pelos indivíduos ao fenômeno ou situação estudada (Merriam, 1998).

A pesquisa foi realizada no segundo semestre de 2015, marcada pela presença constante de um dos pesquisadores no campo de pesquisa, tendo em vista sua relação deste com o grupo investigado. A coleta de dados foi composta por duas entrevistas individuais com a supervisora das serventes, e quatro grupos focais com a equipe completa de limpeza da instituição, composta por dez trabalhadoras. O grupo focal caracteriza-se pela possibilidade de intervenção em tempo real no curso da análise e de confrontar as percepções dos participantes, em suas similitudes e contradições, a respeito de um tema ou grupo de temas relacionados com o objeto de pesquisa (Ruediger \& Riccio, 2004).

Com pressupostos teóricos-metodológicos apoiados na Psicologia do Trabalho, durante a pesquisa de campo utilizou-se também o método da autoconfrontação simples (Clot, 2005; Clot et al., 2001; Clot \& Faita, 2000; Faita, 2001), que consiste nas seguintes etapas: 1) criação do grupo voluntário em que será realizada a análise da atividade; 2) gravação de vídeos; 3) confronto do trabalhador com a gravação de vídeo da sua própria atividade. Após a realização da primeira entrevista com a supervisora e os dois primeiros grupos focais com as serventes, foram gravados vídeos das atividades realizadas pelas serventes, que posteriormente tiveram a oportunidade de assisti-los e se pronunciar a 
respeito das imagens. As filmagens foram realizadas durante a execução das tarefas, em dias, horários e ambientes diferentes, procurando capturar detalhes da prática de trabalho adotada por cada uma delas, observando os instrumentos utilizados, a aplicação e diluição dos materiais de limpeza, e ao mesmo tempo, suas opiniões, sentimentos, expressões de linguagem e corporais, reações, postura e comportamento.

A intenção era que cada uma pudesse ter a experiência de se assistir executando suas tarefas, ouvir seus relatos, refletir sobre o que disseram e fizeram, bem como ter a oportunidade de reformular seus conceitos. Nesse ponto, entende-se que mesmo durante os procedimentos metodológicos, mudanças foram acontecendo no sujeito pesquisado, lembrando Vygotsky quando afirma: "Conheço-me apenas na medida em que sou eu mesmo um outro pra mim" (Vygotsky, apud, Clot, 2007, p.137).

Inicialmente, a supervisora das serventes foi entrevistada, para que pudesse expor como eram divididas as tarefas e como a instituição e a empresa conduziam seu planejamento e execução. A segunda entrevista com a supervisora ocorreu após a realização dos grupos focais com as serventes com o objetivo de entender o impacto da experiência no cotidiano das serventes. Tanto o roteiro das entrevistas quanto dos grupos focais, foram construídos com base nas abordagens trabalhadas no referencial teórico, sempre voltados a uma aprendizagem como processo, como fruto de interação entre os sujeitos, como situado em um contexto social e histórico-cultural, como um pensar vinculado ao fazer, sempre mediado por artefatos físicos ou simbólicos.

A opção em não incluir a supervisora nos grupos focais com as serventes foi para evitar que aquilo que fosse discutido nos grupos não servisse de motivo para algum tipo de punição às trabalhadoras, pois o que elas consideram como meios para alcançar melhor qualidade ou facilitação do trabalho, a instituição considera como inconformidade. No decorrer da pesquisa, a principal preocupação do grupo era ter suas "inconformidades" reveladas à empresa, e manter essas informações em sigilo foi, desde o início, um compromisso assumido pelos pesquisadores. Por esse motivo, os momentos de escuta da supervisora e das serventes foram realizados separadamente. 


\section{Discussão de Resultados}

\section{Como as serventes aprenderam sua profissão?}

A instituição federal de ensino superior, em que o estudo foi realizado, conta com um curso técnico de nível médio e seis cursos de nível superior. Sua estrutura é composta por 11 blocos com salas de aula, laboratórios, ambientes administrativos, auditório e pátio.

A equipe de limpeza é composta por dez serventes contratadas por meio do sistema de terceirização de serviço de apoio técnico-administrativo. A atual empresa, contratada por licitação na modalidade pregão eletrônico, encontra-se em seu segundo ano de atuação e atende também outros postos de trabalho, totalizando vinte e oito trabalhadores terceirizados, sendo um deles o posto de supervisor, responsável por fazer a ponte entre o fiscal de contrato e os trabalhadores terceirizados.

As serventes, em sua maioria, possuem mais de 40 anos de idade e mais de 5 anos de profissão. Dividem-se em turnos de trabalho entre às 6h3omin e 21h, cumprindo tarefas, que segundo a supervisora, estão estabelecidas no plano de serviço de cada uma delas, formulado pela empresa em conjunto com os fiscais de contrato da instituição. Nesse plano de serviço constam detalhadamente os horários, locais e tarefas que deverão ser executas diariamente por cada uma delas.

As tarefas executadas pelas serventes se dividem entre serviços de rotina diária: varrer salas de aulas, recolher lixo dos banheiros, limpar laboratórios e ambientes administrativos, lavar banheiros; faxinas semanais: lavar salas de aula, corredores, laboratórios e ambientes administrativos e lavar vidraças; faxinas semestrais: faxina pesada em todos os ambientes, lavagem de cortinas, entre outros.

Todavia, além dessas tarefas estabelecidas no plano de serviço da instituição, também fazem parte da rotina do grupo outras práticas ou outras formas de execução dessas mesmas tarefas, voluntariamente assumidas por elas, talvez em razão do próprio juízo estético de cada servente. Esse extra que se revela cotidianamente quando elas trazem produtos de limpeza de casa por terem melhor aroma ou por proporcionarem uma limpeza mais “caprichada” representa um detalhamento não prescrito pela instituição, mas que se torna importante, possivelmente pela emoção embutida na execução da tarefa ou também como 
forma de demonstrar seu valor, pois não se pode esquecer que como se trata de uma profissão genuinamente feminina, essas sutilezas podem demonstrar um valor para além do aspecto profissional, mas inclusive, um valor como mulher.

Esse sentimento percebido em campo, essa dedicação empregada pela maioria delas remete ao que Nicolini et al. (2003, p.22) afirma sobre os sujeitos da aprendizagem: "Eles têm corpos; eles tocam, cheiram, saboreiam; eles têm sentimentos e sentidos [...]”. Nesse sentido percebe-se um fazer que não simplesmente cumpre com a prescrição, mas um fazer intimamente vinculado a um pensar, e porque não a um sentir, um sentimento enraizado nas histórias desse aprendizado, um aprender ligado a sentimentos de valorização e reconhecimento que por vezes podem ser traduzidos em afetividade, como declara Elkjaer (2005), um aprender misturado com intuição e emoção.

Quando interrogadas sobre sua trajetória e a maneira como entraram na profissão, observa-se que é comum iniciarem como empregadas domésticas em casas de família, migrando depois para o serviço em empresas. Algumas também já atuaram como operárias em indústrias de confecção, cuidadoras de idosos, babás, entre outras profissões.

Quanto à forma como aprenderam a profissão, a maioria concorda que aprenderam em casa, quando criança ou adolescente, ensinadas pela própria mãe, em seguida, quando da ocasião do casamento, tendo que cuidar da própria casa. Salientam-se as seguintes falas: “Eu perdi minha mãe com 9 anos e tive que aprender sozinha, cuidar da casa e de quatro irmãos pequenos, a gente aprende na vida, né".

A constatação é que se trata de uma profissão que não provém de uma formação específica, como cursos técnicos ou regulares, verifica-se que as entrevistadas consideram a profissão quase como uma atividade inerente ao ser humano. Diferentemente de outras profissões que demandam formação específica - comprovadas por meio de um diploma para o exercício dessa função, são escassos os treinamentos existentes e quando ocorrem, nesse caso a pedido da instituição, geralmente são insuficientes, como foi o caso de um treinamento de duas horas que o grupo recebeu, mas que não resultou em melhorias nas tarefas, justamente por elas considerarem o que foi dito como algo que já era do conhecimento do grupo: "Até o moço que deu a palestra falava assim pra gente: "Ah... vocês sabem como fazer, né?! Sabem mais do que eu”. (risos) 
Essa concepção que a limpeza é algo natural e que qualquer um consegue executar, acentua-se quando se trata da substituição das funcionárias, pois o contrato prevê que em caso de substituição, a nova funcionária só iniciará as atividades no dia seguinte à saída da funcionária desligada, para que assim se cumpram os valores constantes na planilha financeira de cada posto. Desse modo, a nova servente assume as atividades sem uma instrução prévia e passa a adotar procedimentos que estejam de acordo com sua própria concepção de limpeza, adquirida ao longo da sua história de vida e profissional, reforçando uma forte convicção de que o seu "jeito de fazer" é o melhor.

Quando foram questionadas a respeito de quem as teria instruído sobre o serviço quando iniciaram na instituição, notou-se uma sensação de ironia, ou uma estranheza, como se a pergunta fosse um insulto, expressando-se da seguinte forma: "Quem me ensinou? Ninguém, isso aqui eu sei fazer, a gente sabe né, desde...sempre. Eu trabalhei 14 anos em casa de família”.

Mesmo diante dessas afirmações, elas confirmaram tanto no grupo focal, como durante as filmagens, que mesmo depois de tanto tempo executando o mesmo tipo de tarefas ainda continuam a aprender umas com as outras. Em um dos momentos de filmagem, uma das serventes, após terminar de varrer uma sala de aula, na hora de recolher o lixo, percebeu que havia esquecido a pazinha de lixo em outro setor; naquele momento, mesmo um pouco constrangida, entre risos, ela afirma a boca do saco no chão com os dois pés e empurra o lixo para dentro com a vassoura sem o auxílio da pá, e em seguida se justifica: "Justo hoje eu tinha que esquecer a pazinha (risos), mas isso aqui eu aprendi com uma colega minha lá da Empresa $X$, o dia que eu vi ela fazendo isso eu tirei sarro, mas depois disso já fiz a mesma coisa um monte de vez, é melhor que sair procurando a pazinha."

Essas e outras situação mostram que ao presenciar ou participar de uma prática diferente, acabam mudando o próprio jeito de fazê-la foi possível notar que elas trocam experiências principalmente sobre produtos de limpeza e instrumentos de trabalho. Percebe-se que a aprendizagem do grupo, além de cognitiva, pode ser entendida como uma aprendizagem coletiva, em um ambiente de trocas, permeado por uma cultura, uma coletividade que partilha experiências, artefatos, mitos e rituais, como aponta a abordagem cultural da aprendizagem. 
De acordo com a pesquisa de campo, foi possível caracterizar a aprendizagem do grupo como uma aprendizagem baseada na prática, em que o pensar e o fazer estão intimamente ligados, como um conhecimento que precisa ser entendido no contexto do acontecimento, criação ou transferência, próprio de um sujeito social, que ao mesmo tempo pensa, aprende e trabalha.

Isso pode ser notado em cada uma das práticas do grupo: varrendo salas de aula, limpando mobiliários, lavando banheiros, limpando vidros, lavando o piso, entre outros. Durante o acompanhamento das tarefas era percebido com frequência que, mesmo perguntas sobre práticas que estavam executando naquele momento, as serventes tinham dificuldade em explicar qual a forma adotada para aquele tipo de limpeza ou o porquê daquela forma específica, mostrando um saber vinculado sempre a um fazer.

Em suma, cabe lembrar a concepção de aprendizagem da Teoria da Atividade Histórico-Cultural, que não questiona se o conhecimento está na cabeça do indivíduo, mas entende que esse conhecimento é transferido de um indivíduo para o outro em um determinado contexto, por meio de inter-relações mediadas, compreendendo que a aprendizagem é tanto cognitiva quanto cultural (Pereira-Querol et al., 2014).

\section{Quais os impactos, na aprendizagem, de um serviço terceirizado por parte das pesquisadas?}

Ao refletir a importância de tratar as organizações como culturas, e que a cultura armazena as experiências passadas e comunica a aprendizagem para toda a organização, não se pode negar que cultura e aprendizagem estão intimamente conectadas. Para entender o processo de aprendizagem de um grupo, é preciso entender o ambiente em que estão inseridos, pois esses elementos exercem influência no comportamento desses sujeitos. Portanto, olhar para a cultura facilita a compreensão não só da natureza da organização, mas também da natureza da aprendizagem.

Weick e Westley (2004) assinalam que a cultura está inserida na linguagem, palavras, frases, vocábulos e expressões utilizadas pelos grupos, como também nos artefatos, máquinas ou objetos decorativos, nas rotinas, nas trocas sociais, nos rituais e nas saudações entre as pessoas. O invisível torna-se visível por meio do tangível. 
Mas qual cultura se aborda quando se trata de uma empresa terceirizada? A cultura da empresa, cuja razão social consta nas carteiras de trabalho, ou dos rituais e costumes do local no qual o serviço está sendo prestado? O percebido em campo foi uma mistura de fatores de interferência no trabalho das serventes. Da empresa terceirizada provém o aspecto normativo e disciplinar, e da instituição de ensino, todos os outros elementos tangíveis e intangíveis.

Existe no ambiente, por parte dos fiscais de contrato, uma preocupação quando observam que os trabalhadores terceirizados passam a se sentir como funcionários/servidores da própria instituição, pois esse comportamento não é o esperado, inclusive por força de lei, que impede que a instituição crie vínculo empregatício com estes. Mas o que se percebe é que essas trabalhadoras adotam a cultura da organização a qual estão inseridas geograficamente e não aquela registrada em suas carteiras de trabalho.

Ao serem questionadas sobre o quanto conhecem da empresa para a qual trabalham, afirmam não conhecer nada além de um representante, que fez uma única visita, comprometendo-se que retornaria quinzenalmente, mas, nunca mais apareceu. Inclusive na ocasião, esforçaram-se para lembrar o seu nome, porém não conseguiram, demonstrando o distanciamento existente entre elas e a empresa que as contratou. Ante a questão: Quando perguntam para vocês o nome da empresa em que trabalham, em uma ficha cadastral, por exemplo, o que vocês respondem? A resposta unânime foi o nome da instituição de ensino e não da empresa, completando: "A referência que a gente dá é aqui, porque se falar o nome da empresa ninguém conhece"; "Mas, na verdade, é aqui mesmo que a gente trabalha, a gente não tá mentindo [sic]".

Nos relatos, ainda revelaram que, por mais que a supervisora faça essa ponte entre as trabalhadoras e a empresa, elas sentem falta desse contato direto com a empresa: "Tem coisa que a gente quer passar direto pra eles". Vale lembrar que, no momento dessa primeira conversa, uma delas estava com problemas com a supervisora e ficou bastante alterada, aproveitando para desabafar, pois não tinha como fazê-lo diretamente à empresa.

A sensação, nesse aspecto da cultura como conjunto de valores, crenças, expressões tangíveis e intangíveis é que, por mais que o grupo de serventes adote a instituição como provedora dessa cultura, o grupo também partilha da cultura da empresa contratada por meio, dos princípios disciplinares, gerando uma duplicidade de entidades geradoras dessa 
cultura, o que dificulta consideravelmente o processo de trabalho, e talvez também torna mais complexo o próprio processo de aprendizagem. Em entrevista, a supervisora desabafa: "A maior dificuldade de liderar o grupo é por ser um serviço terceirizado. Eles se sentem meio órfãos, se sentem diferentes... dos servidores".

Outro agravante é o fato de que, na maioria das vezes, mesmo a legislação permitindo a renovação contratual por até cinco anos, geralmente as empresas contratadas não permanecem mais do que um ou dois anos nessa instituição, gerando uma frequente troca de empresas, fazendo com que leve um tempo para que os funcionários recontratados se adaptem novamente à empresa vencedora do processo licitatório. Esta pesquisa constatou que quatro serventes já passaram por três empresas, uma delas passou por quatro empresas, e as demais estão na primeira experiência como trabalhadora terceirizada.

Como pode ser notado, a relação existente entre o grupo de trabalhadoras, empresa e instituição está permeada por elementos que acabam por favorecer situações conflituosas que podem impactar na aprendizagem do grupo, lembrando a menção de Antonacopoulou \& Chiva (2007), de que na aprendizagem é preciso considerar o envolvimento do poder e da política.

Se a cultura é compreendida como algo invisível, mas influente no processo de aprendizagem, como uma cultura presente, porém proibida, pode contribuir positivamente no processo de aprendizagem? O aspecto cultural não se dá pelo registro feito nas carteiras profissionais ou contratos, mas por meio de sinais, rituais, artefatos e experiências vividas no ambiente em que as tarefas são desenvolvidas. Além de desencontros de informação, morosidade na solução de conflitos e ausência de representantes da empresa contratada, outros aspectos mais sutis também fazem parte desse processo contínuo da aprendizagem.

Qual a capacidade de interferência da gestão da instituição no processo de aprendizagem?

Como mencionado anteriormente, na tentativa de alcançar melhorias exigidas pela gestão da instituição, a empresa ofereceu às serventes, no início do contrato, um treinamento com duração de duas horas, voltado para a correta aplicação e diluição dos 
produtos de limpeza. Juntamente com esse treinamento, a instituição implantou um sistema de controle de distribuição visando à redução do consumo de produtos de limpeza.

Na primeira entrevista, a supervisora afirmou que após o treinamento, as serventes passaram a adotar entre elas um padrão único de aplicação e diluição dos produtos, dando a impressão que o problema havia sido resolvido. Quanto à execução das tarefas, tanto a supervisora como as serventes relatam que todas seguiam um mesmo padrão, exclamando: “Limpeza é tudo igual, né!”.

Destarte, contrariando as afirmações, as filmagens demonstraram o oposto, inclusive gerando um desconforto entre elas no momento da autoconfrontação, pois ao perceberem que cada uma adotava técnicas, produtos e quantidades diferentes, passaram a defender o próprio método e criticar o da colega. Aqui, é possível lembrar do princípio da multivocalidade da Teoria da Atividade Histórico-Cultural, o qual considera que o sistema de atividade é "sempre uma comunidade com múltiplos pontos de vista, tradições e interesses" (Engeström, 2001, p. 136).

Na prática cotidiana da limpeza, observou-se que cada uma utilizava diferentes produtos no mesmo tipo de ambiente, em quantidades e formas de diluição distintas. Houve uma filmagem que registrou duas serventes, ao mesmo tempo, lavando o chão do mesmo laboratório, com o mesmo nível de sujeira, e cada uma esguichava produtos e quantidades diferentes no piso.

Nenhuma delas utiliza recipientes medidores ou algum método específico para diluição dos produtos. Algumas esguicham o produto diretamente na superfície a ser limpa, outras diluem na água, algumas misturam dois produtos diferentes na mesma embalagem, bem como utilizam tipos de rodos e vassouras diferentes e optam por panos de limpeza de diferentes qualidades. Nas filmagens, observou-se que algumas serventes não utilizavam os panos de limpeza comprados pela instituição, e sim outros tipos de panos, trazidos de suas casas, alegando os seguintes motivos: por serem de melhor qualidade, tamanho maior, mais fáceis de lavar, não deixam resíduo nas superfícies, entre outros. Portanto, verifica-se que o processo é personalizado por elas, e que o foco é no resultado final, já que o que importa é ficar limpo, independente dos meios ou da quantidade de material utilizado: "É bom quando a pessoa gosta do serviço da gente e fala assim: "Olha, ela faz o serviço bem feito, como se fosse na casa dela"! 
Quanto à eficácia do treinamento proposto, visando à padronização dos processos para a redução do consumo, diferente da afirmação da supervisora, as serventes, ao serem interrogadas sobre o quanto o curso alterou no seu processo de trabalho, repetiam as respostas: "Não mudou nada. Tudo que ele falou nós já sabia [sic]”.

O tempo todo nota-se o quanto cada uma delas confia no próprio método e, mesmo a instituição tentando controlar o processo, na prática elas encontram meios de empregar os próprios conceitos para alcançar o objetivo. Diferente do que afirmaram no grupo focal, sobre manter o mesmo padrão, durante as filmagens as falas já eram as seguintes: "Limpar não é segredo, mas cada uma tem o seu jeito"; "Eu mesmo, sou de lavar. Meu marido mesmo fala: "Você com a mangueira na mão é um perigo". Eu já até enferrujei o pé da mesa em casa por ficar jogando água”; "Eu vou misturando as coisas e fazendo teste”.

Até que ponto a organização está no controle? Mesmo havendo por parte das serventes um receio pelo fato das filmagens estarem sendo feitas pela fiscal de contrato, o que representava um perigo posterior de sanção - fato também expresso nos grupos focais - elas mantiveram seu comportamento e forma de trabalho.

Entende-se que tal situação mantém relação com o princípio de criação e externalização da Teoria da Atividade, conforme assevera Engeström (1999) sobre a existência de um consenso em que o aspecto mais importante da atividade humana é a sua criatividade e sua capacidade de ultrapassar ou transcender as restrições e instruções dadas. Aqui, a aprendizagem passa a ser pensada enquanto espaço de construção do indivíduo, e em sua potencialidade de vir a ser. "Neste sentido, um aspecto primordial da condição humana, é a criação e o uso dos estímulos auxiliares ou artificiais que garantem a criação de uma situação inédita, cujas reações são alteradas pela intervenção humana ativa” (Vygotsky, 1991, p.39).

\section{Como conduzir o processo de aprendizagem para solucionar a problemática?}

Em campo, foi possível notar o sentimento de pertencimento das serventes em relação ao cumprimento das suas tarefas, práticas sociais e até mesmo na utilização e adequação dos próprios instrumentos de trabalho. Além de encontrá-las com panos de limpeza diferentes daqueles comprados pela instituição, trazidos de suas casas, ou com rodinhos adaptados, 
com cabos alongados com mais de uma fibra, presas com elásticos no esfregão, percebe-se que existe uma resistência ao uso de luvas, com a justificativa de que "amarram o serviço", e também às calças do uniforme e sapatos de segurança fornecidos pela empresa, por "serem feios e desconfortáveis".

Excluindo o fato de que é natural os trabalhadores apresentarem certa resistência ao uso de EPI's - Equipamento de Produção Individual -, nota-se que essa resistência ao uso do uniforme poderia ser também entendida com uma forma essas trabalhadoras se misturarem mais facilmente entre servidores da instituição, eliminando elementos simbólicos que, de maneira geral, as distinguem e, dessa forma, minimizarem o sentimento relatado pela supervisora: “...Eles se sentem meio órfãos, se sentem diferentes... dos servidores”.

Além disso, o tempo todo percebe-se que mesmo produtos com baixa eficiência, ou instrumentos pouco funcionais, são facilmente modificados por elas para que se alcance o objetivo final, nesse caso, a limpeza do ambiente. É o sujeito transformando o ambiente em que vive em meio a uma dinâmica de trocas com elementos humanos e não-humanos, imprimindo sua marca.

No último grupo focal, utilizando a técnica da autoconfrontação, constatou-se que, após assistirem as filmagens e ouvirem trechos de suas falas nos grupos focais anteriores, as serventes relataram a importância de conhecer o trabalho das outras colegas e se surpreenderam com o quanto cada uma delas trabalham de maneira distinta: "Nem a gente sabia que fazia assim tão diferente da outra"; "Nossa! Eu achava que eu fazia tudo certinho". Percebe-se, nesse ponto, a relevância de oportunizar um espaço de autoconhecimento e reflexão.

Após terem relutado e, muitas vezes desconfiado do objetivo da pesquisa, percebeu-se uma satisfação das serventes em terem participado da pesquisa. Esse contentamento foi expresso por meio das seguintes falas: "Nunca ninguém se interessou pelo nosso trabalho. As pessoas que cuidam não tão nem aí com a gente, mas você ouviu a gente”. Supervisora: "Eu acho que isso aproximou mais elas da universidade, agora elas acha que tem valor dentro da universidade, acho que elas tão se sentindo mais liberta pra trabalhar, como se elas trabalhassem numa empresa normal, com menos medo, talvez por essa aproximação”.

Por fim, o momento de reflexão avança para um despertar, como se pode perceber na seguinte fala: "Acho que ainda dá pra melhorar muita coisa". 
Diante da realidade presenciada, sobretudo de um certa resistência por parte das serventes, quando se trata de padronização de tarefas, seria preciso pensar em outros modos de intervenção, que não os treinamentos ou imposições normativas, inclusive vinculados a sanções disciplinares, uma vez que diversas tentativas nesse sentido já fracassaram.

Como então encontrar uma forma capaz de intervir num processo tão cristalizado, em uma aprendizagem em que prática profissional e história de vida estão intimamente ligadas? Nesse caso, metodologicamente, isso poderia ser melhor compreendido por meio de propostas que gerem mudanças por meio reflexões coletivas e participativas. Mudança não apenas na atividade, mas também no sujeito da aprendizagem.

Portanto, julga-se que as metodologias intervencionistas (Cassandre \& Godoi, 2014; Pereira-Querol et al., 2014; Sannino, 2011; Engeström, 2001) estariam mais próximas de dar conta das transformações necessárias, uma vez que os sujeito envolvidos, por meio de técnicas próprias, seriam levados a refletir sobre as práticas adotadas, e a longo prazo pensar em novas possibilidades, a ponto de transformar não só sua realidade profissional, mas também pessoal.

Com base nessa necessidade de mudança, ainda na pesquisa de campo, foi iniciado um trabalho de esclarecimento do grupo: como um primeiro passo de uma trajetória participativa em busca de melhorias, o grupo foi levado a uma visita ao almoxarifado da instituição na qual pode conhecer pessoalmente a gama de produtos e sua forma de aquisição dos mesmos, por meio de uma breve explanação feita pelos membros da comissão de licitação.

$\mathrm{Na}$ ocasião, as serventes tiraram dúvidas, expressaram suas opiniões quanto à qualidade de alguns itens e sugeriram novos produtos. Nessa interação notou-se um ganho tanto para as serventes como para a comissão de licitação que, por mais que soubessem da insatisfação existente em relação a alguns produtos, puderam sentir isso de perto.

No decorrer da pesquisa, diversas sugestões foram dadas pelo grupo, algumas foram implementadas e encontram-se em fase de teste e outras, que necessitam de mais tempo para implantação, mas que poderão fazer parte de futuros trabalhos, como por exemplo, encontros sistemáticos com as serventes, supervisora e fiscais de contrato para discutir a aplicação e diluição dos produtos com objetivo de produzir uma lista de materiais de limpeza mais enxuta e com produtos de melhor qualidade. 


\section{Considerações Finais}

Nesse intenso processo de encontrar respostas para as diferentes perguntas acerca da AO, destaca-se a importância de estar aberto a este mundo de possibilidades ao qual se refere Bitencourt \& Azevedo (2006). Especialmente quando se vai a campo em busca de elementos que justifiquem determinados conceitos, é preciso estar atento aos aspectos objetivos e subjetivos do processo e ter consciência das próprias limitações.

Diante disso, a partir da experiência vivenciada, passa a ser possível pensar numa aprendizagem que, antes de chegar a ser organizacional, passa pelo individual, pelo cognitivo, pelo tácito e pelo explícito, caminha pelas práticas cotidianas, pelas interações sociais e pelo coletivo. Um coletivo que inclui a mente, o corpo, os símbolos, os artefatos, o juízo estético, o poder, a política, a história de vida, a intuição e a emoção. Enquanto está nesse campo de troca, essa aprendizagem é testada, é experimentada, é modelada, e o tempo todo vai sendo mediada pela cultura, pelas normatizações, expectativas, e sem que ninguém se de conta, ela vai indo e vindo, do mental para a prática, do individual para o coletivo, em um meio repleto de contradições e vai, de forma imprevisível, transformando tudo por onde passa, tanto o sujeito quanto o seu meio, tanto no contexto de trabalho quanto no contexto pessoal.

Na prática das serventes, foi possível perceber que a aprendizagem se dá por meio das interações sociais, mediada por artefatos e cercada por elementos que interferem nesse processo de forma constante. $\mathrm{O}$ fato de a inserção profissional estar vinculada a sua própria história de vida, torna essa apropriação do conhecimento quase como um forma de vida, o "fazer como se faz em casa" legitima a qualidade do serviço e concede a quem pratica uma espécie de selo de qualidade simbólico e tentar questionar essas práticas de forma abrupta e sancionadora talvez não seja a melhor opção.

O fato de se sentirem "órfãs" pela distância existente entre o grupo e a empresa contratante e "adotadas" pela instituição de ensino são aspectos que dificultam um posicionamento definido no próprio trabalho, como se interferisse na identidade profissional de cada uma delas, justificando determinados comportamentos e sentimentos e interferindo no processo de aprendizagem. 
Um dos aspectos importantes da pesquisa foi entender que a aprendizagem é algo que vai além de informações transmitidas e assimiladas, ou de prescrições que são cumpridas, pois além do acordo explícito que determina as tarefas a serem cumpridas, também foi possível perceber a existência de um acordo tácito, firmado entre elas, com elas mesmas e com o próprio trabalho, que se mostra como uma necessidade de fazer além daquilo que está prescrito, um "deixar brilhando", "deixar cheiroso", que talvez esteja ligado à emoção vivida no início desse aprendizado, quando crianças, ou quando tornavam-se mulher.

Por isso a importância de compreender que em aprendizagem organizacional, nem sempre se trata de solucionar problemas ou prescrever procedimentos, existe uma emoção atrelada e um juízo estético fortemente condicionado à cultura na qual o sujeito está inserido que, por vezes influencia diretamente o processo de aprendizagem, e talvez esse seja um dos achados mais valiosos da experiência: uma aprendizagem que tem como foco um objetivo, que brota do coletivo, que está permeada por histórias de vida, por convenções culturais e também emoção, e que no final das contas, talvez seja a grande responsável por despertar a capacidade criadora e o comprometimento do sujeito com a aprendizagem e consequentemente com a atividade.

$\mathrm{Na}$ análise dos dados, outros elementos significativos puderam ser observados: a possibilidade de se despertar no grupo, por meio de ferramentas adequadas, como foi o recurso da autoconfrontação, a capacidade de reflexão sobre a própria atividade; um sentimento de satisfação do grupo em ter sido alvo de atenção em um espaço institucional que geralmente evidencia os profissionais com alto grau de instrução, como se a preocupação demonstrada durante a pesquisa com um trabalho considerado de baixa complexidade tivesse sido uma forma de reconhecer o valor do trabalho executado no cotidiano desses sujeitos; e por fim um sinal de abertura com relação a um repensar das formas de execução das tarefas e utilização de produtos.

Isso faz emergir uma necessidade de se pensar em meios que sejam capazes de, a partir desses elementos, criar um espaço de aprendizagem, que além de implementar melhorias, promovam também o próprio sujeito. Além disso, no processo de reflexão quanto às práticas do grupo, talvez seja possível pensar na possibilidade de que determinadas táticas podem estar sendo adotadas como forma de resistência individual ou até mesmo do próprio grupo, marcando essa relação entre elas, a empresa e a instituição. 
Diante desse contexto, uma possibilidade seria pensar na potencialidade de vir a ser, proposta pela Teoria da Atividade, na qual o sujeito é respeitado em sua individualidade, em seu potencial de aprendizagem e enxergado como um agente inserido num meio de trocas e transformações. Além disso, nas metodologias intervencionistas, o papel do pesquisador também é reconfigurado, pois passa a exercer um comportamento proativo com as pessoas e com o objeto de estudo, desenvolvendo a função de mediador e facilitador, assumindo seu caráter ativista no processo de concepção e implementação das pesquisas, até o ponto de se tornar também um agente de mudança.

Diante disso, mesmo que a intenção do estudo não tenha sido prescritiva, a proposta é que se dê continuidade a esse trabalho, de forma a criar um espaço para que as serventes, independente da empresa a qual estejam vinculadas, possam participar do processo de melhorias, partilhando experiências, analisando seus dilemas e contradições e remodelando a atividade, assim como propõe as metodologias intervencionistas baseadas na Teoria da Atividade Histórico-Cultural.

Um fator significativo é que a Teoria da Atividade Histórico-Cultural não está focada no controle de erros, mas está interessada em implementar uma análise histórica da atividade, em um sistema de atividade dotado de multivocalidade, respeitando caráter lúdico e criador da aprendizagem, porque a reconhece como mediada por artefatos concretos e simbólicos; assim, está interessada em analisar os dilemas, buscando as verdadeiras contradições, demonstrando aos envolvidos de que maneira aquela atividade específica está ligada às outras atividades da organização - rede dos sistemas de atividade - e por fim redescobrindo ou renovando seu motivo e objeto. Lembra-se que o que hoje tem sido visto como inconformidade pela organização, amanhã pode servir para a renovação da própria atividade.

Em relação ao objetivo proposto pelo estudo, de conhecer o processo de aprendizagem das serventes de limpeza terceirizadas de uma instituição pública de Ensino Superior, é possível afirmar que este foi alcançado, mas que longe de ser conclusivo, ele abre caminho para novos desdobramentos que poderão ser trabalhados em futuros estudos, pois por se tratar de fenômenos sociais, e por isso complexos e dinâmicos, diversos aspectos ainda carecem de aprofundamento. 
Em resumo, a experiência deste estudo, além transformar a concepção dos pesquisadores em relação aos sujeitos da pesquisa, possibilitou, por meio do contato com as diversas abordagens, a construção de um melhor entendimento sobre $\mathrm{AO}$, não de forma conclusiva ou absoluta, obtendo respostas prontas, ou conceitos únicos, mas a possibilidade de, a partir da aproximação de uma prática, pensar a Aprendizagem de uma forma dinâmica e dialética, capaz de levar a um caminho de novas descobertas, porque talvez esse seja um ponto forte do processo de aprendizagem, o fato de que aprender não é resolver ou estancar um problema mas sim, de alguma forma, criar condições de lidar com as problemáticas presentes e futuras, pois a contradição sempre vai existir, e ter consciência de que esse ciclo é permanente é o primeiro passo. 


\section{Referências}

Antonacopoulou, E., \& Chiva, R. (2007).The Social Complexity of Organizational Learning: The Dynamics of Learning and Organizing. Management Learning, 38(277), 277-295.

Antonello, C. S., \& Godoy, A. S. (2010). A Encruzilhada da aprendizagem organizacional: uma visão multiparadigmática. Revista de Administração Contemporânea, Curitiba, $14(2), 310-332$.

Antonello, C. S., \& Godoy, A. S. (2011). Aprendizagem Organizacional e Raízes da Polissemia. In C. S. Antonello \& A. S. Godoy (Eds.) Handbook de Aprendizagem Organizacional. Porto Alegre: Bookman, 31-50.

Argyris, C., \& Schön, D. A. (1978) Organizational learning: a theory of action perspective. Reading, Massachusetts: Addison-Wesley.

Argyris, C., \& Schön, D. A. (1996) On organizational learning: theory, method, and practice. Reading, Massachusetts: Addison-Wesley, 2.

Bitencourt, C. C., \& Azevedo, D. (2006). O futuro da aprendizagem organizacional: possibilidades e desafios. Revista de Administração de Empresas, São Paulo, 46, 110-112, Edição Especial.

Cassandre, M. P., \& Godoi, C. K. (2014). Metodologias Intervencionistas da Teoria da Atividade Histórico-Cultural: Abrindo Possibilidades para os Estudos Organizacionais. RGO. Revista Gestão Organizacional (Online), 6, 11-23.

Cassandre, M. P., Pereira-Querol, M. A., \& Bulgacov, Y. L. M. (2012). Metodologias Intervencionistas: Contribuição Teórico-metodológica dos Princípios Vigotskyanos para Pesquisa em Aprendizagem Organizacional. In 26 Encontro da Associação Nacional de Pós-Graduação e Pesquisa em Administração, Rio de Janeiro.

Cook, S. D. N., \& Yanow, D. (1993). Culture and organizational learning. Journal of Management Inquiry, 2(4), 373-390. 
Clot, Y., \& Faïta, D. (200o). Genre et style en analyse du travail. Travailler, Paris, (4), 7-42.

Clot, Y., Faïta, D., Fernandez, G., \& Scheller, L. (2001). Entrétiens en autoconfrontation croisée: une méthode en clinique de l'activité. Éducation Permanente, Paris, (146), 17-25.

Clot, Y., Faïta, D., Fernandez, G., \& Scheller, L. (2005). L'autoconfrontation croisée en analyse du travail: l'apport de la théorie bakhtinienne du dialogue. In L. Filliettaz, J-P. Bronckart (Ed.). L'analyse des actions et des discours en situation de travail: Concepts, méthodes et applications. Louvain-la-Neuve: Collection Bibliothèque des Cahiers de l'Institut de Linguistique de Louvain (BCILL), 37-55.

Clot, Y., Faïta, D., Fernandez, G., \& Scheller, L. (2007). A função psicológica do trabalho. Petrópolis: Vozes.

Creswell, J. W. (2014). Investigação qualitativa e projeto de pesquisa: Escolhendo entre cinco abordagens. São Paulo: Penso Editora.

Daft, R. L., \& Weick, K. E. (1984). Toward a model of organizations as interpretation systems. Academy of Management Review, 9(2), 284-295.

Elkjaer, B. (2005). Organizational learning: the third way. Management Learning, 35(4), 419434 .

Engeström, Y. (1996). Developmental work research as educational research: Looking ten years back and into the zone of proximal development. Nordisk Pedagogik: Journal of Nordic Educational Research, 16, 131-143.

Engeström, Y. (1999). Activity theory and individual and social transformation. In Y. Engestrom, R. Miettinen, R. L. Punamaki (Eds.), Perspectives on activity theory. Cambridge: University Press, 19-38.

Engeström, Y. (2001). Expansive Learning at Work: Toward an activity theoretical reconceptualization. Journal of Education and Work, 14(1), 133-156.

Faïta, D. (2001). Genres d'activité et styles de conduite. In A. Borzeix, B. Fraenkel (Dir.). Langage et travail: communication, cognition, action, Paris: CNRS Éditions, 263-284. 
Fiol, C. M., \& Lyles, M. A. (1985). Organizational learning. Academy of Management Review, $10(4), 803-813$.

Freitas, S.M.F., \& Godoi, C. K. (2008). A Aprendizagem Organizacional sob a Perspectiva Sócio-Cognitiva: Contribuições de Lewin, Bandura e Giddens. Revista de Negócios, 13, 40-55.

Geiger, D. (2009). Revisiting the Concept of Practice: Toward an Argumentative Understanding of Practicing. Management Learning, 40(2), 129-144.

Jarzabkowski, P. (2005). Strategy as practice: an activity-based approach. London: Sage Publications.

Levitt, B., \& March, J. G. (1988). Organizational learning. Annual Review of Sociology, 14, 319340.

Merriam, S. B. (1998). Qualitative research and case study applications in education. San Francisco: Jossey Bass.

Nicolini, D., Gherardi, S., \& Yanow, D. (2003). Introduction: Toward a Practice-Based View of Knowing and Learning in Organizations. In Nicolini, D., Gherardi, S. \& Yanow, D. (Eds.) Knowing in organizations: a practice-based approach, London: M. E. Sharpe.

Nogueira, R. A., \& Odelius, C. C. (2015). Desafios da Pesquisa em Aprendizagem Organizacional. Cadernos EBAPE.BR, 13(1), artigo 5.

Paes de Paula, A. P., \& Palassi, M. P. (2007). Subjetividade e simbolismo nos estudos organizacionais: um enfoque histórico-cultural. In A. P. Carrieri, \& L. A. S. Saraiva (Org.). Simbolismo organizacional no Brasil. São Paulo: Atlas.

Pereira-Querol, M. A. P., Cassandre, M. P., \& Bulgacov, Y. L. M. (2014). Teoria da Atividade: Contribuições Conceituais e Metodológicas para o Estudo da Aprendizagem Organizacional. Gestão \& Produção, 21(2), 405-416. 
Pereira-Querol, M. A., Jackson Filho, L. M., \& Cassandre, M. P. (2011). Change Laboratory: uma proposta metodológica para pesquisa e desenvolvimento da Aprendizagem Organizacional. Administração: Ensino e Pesquisa, 12(4).

Reckwitz, A. (2002). Toward a theory of social practices: a development in culturalist theorizing. European Journal of Social Theory, 5(2), 243-263.

Ruediger, M. A., \& Riccio, V. (2004). Grupo focal: método e análise simbólica da organização e da sociedade. In Vieira, M. M. F., Zouain, D. M. Pesquisa qualitativa em administração. Rio de Janeiro: Editora FGV, 151-172.

Sannino, A. (2011). Activity theory as an activist and interventionist theory. Theory $\mathcal{E}$ Psychology, 1-27.

Veresov, N. (2010). Introducing cultural historical theory: main concepts and principles of genetic research methodology. Cultural-Historical Psychology, 4, Moscow State University of Psychology and Education, Russia, 83-90.

Vygotsky, L. S. (1978). Mind in society: the development of higher mental processes. Cambridge, MA: Harvard University Press.

Vygotsky, L.S. (1991). Internalização das funções psicológicas superiores. In M. Cole et al. (Coords.). Formação social da mente: o desenvolvimento dos processos psicológicos superiores. (4. ed.). São Paulo: Martins Fontes.

Weick, K. E., \& Westley, F. (2004). Aprendizagem organizacional: confirmando um oximoro. In: Clegg, S., Hardy, C., Nord, W. R. (Org.) Handbook de estudos organizacionais, 3, São Paulo: Atlas, 361-388

Weisinger, J. Y., \& Salipante, P. F. (2000). Cultural knowing as practicing: Extending our conceptions of culture. Journal of Management Inquiry, 9(4), 376-39o.

Whittington, R. (2006). Completing the practice turn in strategy research. Organization Studies, 5, 613-634. 
Teoria e Prática em Administração, v. 7, n. 1, jan/jun 2017- ISSN: 2238-104X Reflexões sobre Água, Sabão e Conhecimento: Aprendizagem Organizacional na Prática das Serventes de Limpeza de uma Instituição de Ensino Federal Santos \& Cassandre

DOI: http://dx.doi.org/10.21714/2238-104X2017v7i1-3108 Submissão: 17/Out/2016 - Segunda versão: 28/Mar/2017 - Aceite: 11/Abr/2017

Yanow, D. (2000). Seeing Organizational Learning: A 'Cultural' View. Organization, 7(2), $247-268$ 